\title{
Kivi İlaveli Dondurmaların Bazı Fizikokimyasal, Reolojik ve Duyusal Özelliklerinin Belirlenmesi
}

\author{
Tuba ERKAYA KOTAN ${ }^{1}$ Bayram ÜRKEK ${ }^{2^{*}}$ Mustafa ŞENGÜL ${ }^{3}$ \\ ${ }^{1}$ Atatürk Üniversitesi, Erzurum Meslek Yüksekokulu, Gıda İşleme Bölümü, Erzurum, Türkiye \\ ${ }^{2}$ Gümüşhane Üniversitesi, Şiran Mustafa Beyaz Meslek Yüksekokulu, Gıda İşleme Bölümü, Gümüşhane, Türkiye \\ ${ }^{3}$ Atatürk Üniversitesi, Ziraat Fakültesi, Gıda Mühendisliği Bölümü, Erzurum, Türkiye
}

(*Sorumlu yazar e-mail: bayramurkek@gumushane.edu.tr)

DOI: 10.17097/ataunizfd.393285

Geliş Tarihi: 12.02.2018

Kabul Tarihi: 19.05.2018

\begin{abstract}
ÖZ: Bu çalışmada farklı oranlarda (\%4, \%8, \%12,\%16 ve \%20) kivi meyvesi ilave edilerek üretilen dondurmaların bazı fiziksel, kimyasal, reolojik ve duyusal özellikleri araştırılmıștır. Kivi oranının artması ile dondurma örneklerinin kurumadde (\%), kül ve pH değerlerinin azaldığı, ilk damlama ve tamamen erime zamanları ile asitlik (\%) değerlerinin yükseldiği belirlenmiştir. Dondurmaların $\mathrm{C}$ vitamini içerikleri ise kivi ilavesinden önemli derece etkilenmiş $(\mathrm{P}<0.01)$ ve kivi oranının artışına bağlı olarak $\mathrm{C}$ vitamini içeriği de artmıştır. Dondurma örnekleri reolojik açıdan incelendiğinde, kontrol örneğinin kıvam katsayısı kivi ilave edilen dondurma örneklerine göre daha düşük bulunmuştur. Tüm dondurma örnekleri psödoplastik davranış sergilemiştir. Duyusal açıdan, \%4 oranında kivi ilave edilmiş dondurma örneğinin renk, sakızımsı yapı, tekstür, lezzet, ağızda erime, erimeye dayanıklılık ve genel kabul edilebilirlik puanlarının diğer örneklere göre daha yüksek olduğu ortaya konulmuştur. Araştırma sonucunda, dondurma üretiminde kivi kullanımının dondurmanın C vitamini içeriği ve kıvamı üzerine olumlu bir etkiye sahip olduğu tespit edilmiştir.
\end{abstract}

Anahtar kelimeler: Kivi, dondurma, C vitamini, reolojik özellikler, duyusal özellikler

\section{Determination of Some Physicochemical, Rheological and Sensory Properties of Kiwi Added Ice Creams}

\begin{abstract}
In this research, the physical, chemical, rheological and sensory properties of ice creams of kiwi addition at different ratios $(4 \%, 8 \%, 12 \%, 16 \%$ and $20 \%)$ were investigated. The increment of kiwi rations led to the decrease of dry matter, ash and $\mathrm{pH}$ values, but the first dripping and complete melting times, titratable acidity values increased. Vitamin $\mathrm{C}$ content of ice cream samples was significantly affected by addition of kiwi $(\mathrm{P}<0.01)$, and it increased depending upon kiwi amount. The consistency coefficient of control sample was lower according to kiwi added ice cream samples. All ice cream samples had pseudoplastic behaviour. The color, gumming, texture, flavour, melting in mouth, resistance to melting and general acceptability score of the sample $4 \%$ kiwi added ice cream were higher compared with other samples. Consequently, the research shown that kiwi usage at ice cream production has positive effect on vitamin $\mathrm{C}$ content and consistency of ice cream.
\end{abstract}

Keywords: Kiwi, ice cream, vitamin C, rheological properties, sensory properties

\section{GíRiş}

Son yıllarda kaliteli ve sağlıklı gıdalara olan talep giderek artmaktadır. Tüketiciler genellikle doğal bileşenlere sahip, besleyici ve sağlıklı gıdaları tercih etmektedirler. Tüketicilerin isteklerini karşılayabilmek için gıda üreticileri her geçen gün yeni bir ürün geliştirme çabasındadır (Sikora vd., 2013). Dondurma endüstrisindeki yeni ürün geliştirme çabaları son yıllarda hızla artmaktadır (Soukoulis vd., 2014). Dondurma yüksek düzeyde protein ve yağ içeriğine sahip olduğundan değerli bir süt ürünüdür. Dondurma besinsel ve kalori değeri yüksek bir ürün olmasına karşın doğal antioksidan maddeler, bazı mineraller ve diyet lifi bakımında yetersizdir. Bu yüzden dondurma üreticilerinin doğal ve yeni bir dondurma üretme eğilimi gittikçe artmaktadır (Erkaya vd., 2012). Yeni ve fonksiyonel dondurma geliştirmek amacıyla birçok araştırma yapılmış (Soukoulis vd., 2009; Erkaya vd., 2012; Sun-Waterhouse vd., 2013; Çakmakçi vd., 2016) ve yapilmaya da devam edilmektedir.

Fonksiyonel ve meyveli dondurmalara tüketicilerin talepleri her geçen gün artmaktadır. Bu nedenle son yıllarda market raflarında değişik meyveli dondurmalar yer almaya başlamıştır. Meyveli dondurmaların, ilave edilen meyveler nedeniyle doğal antioksidan madde, mineral, vitamin, lif ve doğal renklendirici içeriklerinin arttığı, kolesterol ve yağ içeriklerinin ise azaldığ $\breve{g}_{1}$ ifade edilmektedir. (Kavaz Yuksel, 2015). Meyve ve sebze tüketiminin birçok hastalığın tedavisinde ve engellenmesinde önemli bir rolü vardır (Park vd., 2011). Kivi de insan sağlığı üzerinde olumlu etkileri olan meyvelerden biridir (Ekşi ve Türkmen Özen, 2012)

Kivi üretimi ülkemizde giderek yaygınlaşmakta olup, özellikle Doğu Karadeniz Bölgesi'nin önemli tarımsal ürünlerinden bir tanesidir (Kılıç ve Sıray, 2016). Kivi antioksidan maddeler, renk pigmentleri, baz1 mineral maddeler, vitaminler ve diyet lifi bakımından zengindir (Du vd., 2009; Park vd., 2011; Ekşi ve Türkmen Özen, 2012). Özellikle C vitamini bakımından zengin olan kivi, aynı zamanda zengin renk pigmentlerine de sahiptir (Du vd., 2009; Ekşi ve Türkmen Özen, 2012). Kivi sahip olduğu bu 
özelliklerle hastalıklara karşı koruyucu (Park vd., 2011) ve fonksiyonel bir meyvedir (Ekşi ve Türkmen Özen, 2012). Bu çalışmada fonksiyonel bir ürün elde edebilmek amaciyla farklı oranlarda kivi ilavesiyle $(\% 4, \% 8, \% 12, \% 16$ ve $\% 20)$ dondurma üretilmiş ve üretilen dondurmaların bazı fiziksel, kimyasal, reolojik ve duyusal özellikleri araştırılmıştır.

\section{MATERYAL VE METOT}

\section{Materyal}

Dondurma üretiminde kullanılmış olan süt ve krema, Atatürk Üniversitesi Ziraat Fakültesi İşletme Müdürlüğü'nden temin edilmiş olup, duyusal ve teknolojik özellikleri dondurma yapımına uygun olan inek sütü kullanılmıştır. Üretimde kullanılan kivi, süttozu, şeker, stabilizatör (salep) ve emülgatör (mono ve digliseritler) ise piyasadan temin edilmiştir. Araştırma için kullanılan deneme dondurma örnekleri Atatürk Üniversitesi Ziraat Fakültesi G1da Mühendisliği Bölümü Pilot Süt fabrikasında tarafımızca üretilmiştir.

\section{Metot}

\section{Dondurma Üretimi}

Dondurma üretiminde kullanılan sütün yă̆ oranı krema ilavesiyle \%5'e ayarlanmış ve daha sonra 12 kısma bölünmüştür. Her bir kısma \%15 şeker, $\% 3.75$ süttozu, $\% 0.7$ salep, $\% 0.2$ emülgatör ilave edilerek $85^{\circ} \mathrm{C}$ 'de $25 \mathrm{sn}$ süreyle pastörize edilmiştir. Pastörizasyondan sonra elde edilen miksler $4{ }^{\circ} \mathrm{C}$ 'de 24 saat süreyle olgunlaştırılmıştır. Dondurmaya ilave edilecek kiviler yıkandıktan sonra kabukları soyulmuş ve rondodan geçirilmiştir. Dondurma makinesinde kontrol örneği $(K)$ dişındaki diğer mikslere rondodan geçirilmiş kivilerden \%4 (KV4), \%8 (KV8), \%12 (KV12), \%16 (KV16) ve $\% 20$ (KV20) oranlarında ilave edilmiştir. Dondurma makinesinden çıkan dondurmalar daha sonra "-24 ${ }^{\circ} \mathrm{C}$ ' de" bir gece sertleştirildikten sonra "$18^{\circ} \mathrm{C}$ ” de muhafaza edilmiştir.

\section{Dondurma Örneklerinin Fiziko-kimyasal} Analizi

Süt ve dondurna örneklerinde \% kurumadde oranı gravimetrik yöntem, asitlik miktarı $\left({ }^{\circ} \mathrm{SH}\right)$ titrasyon yöntemi ve \% kül miktarı ise yakma yöntemi kullanılarak belirlenmiştir. $\mathrm{pH}$ birleşik elektrotlu $\mathrm{pH}$ metre ile ve \% yă oranı ise Gerber yöntemiyle belirlenmiştir (Demirci ve Gündüz, 1994).

İlk damlama zamanı ve tam erime süreleri Güven ve Karaca (2002) tarafindan belirtilen yönteme göre belirlenmiştir. Dondurma örneğinden $25 \mathrm{~g}$ tartıldıktan sonra, $0.9 \mathrm{~mm}$ çapında delikli bir süzgecin altında darası alınmış $250 \mathrm{ml}$ 'lik behere konularak oda sicaklığında 2 saat süreyle erimeye bırakılmıştır. Daha sonra ilk damlama süresi ve tam erime süreleri belirlenmiş ve sonuçlar sn olarak kaydedilmiştir.

Dondurma örneklerinde viskozite Brookfield Viscometer Model DV-II cihazı ile $+4^{\circ} \mathrm{C}$ 'de, 6 numaralı başlık kullanılarak 20, 30, 50, 60 ve 100 rpm'de ölçülmüştür. 30 sn sürelik rotasyon yapıldıktan sonra sonuçlar cP olarak belirlenmiştir (Akin vd., 2007). Dondurma örneklerinin reolojik davranışları "power law" modeli kullanılarak aşağıdaki formülle hesaplanmıştır. $\mathrm{Bu}$ formülde $\eta$ görünür viskoziteyi (Pa.s), $K$ kıvam indeksini, $\gamma$ kayma hızını (rpm), $\mathrm{n}$ akış davranış indeksini göstermektedir (Steffe, 1967).

$$
\eta=K \gamma^{(\mathrm{n}-1)}
$$

C vitamini içeriği Özkan vd. (2007) tarafindan belirtilen titrasyon yöntemiyle belirlenmiştir. Örneklerin askorbik asit miktarı tayininde 2.6diklorofenolindofenol kullanılmıştır. Homojenize edilen örneklerden 15-20 g tartılarak $100 \mathrm{~mL}$ 'lik balon jojeye aktarılmıştır. Balon joje çizgisine kadar \%3'lük metafosforik asit ile tamamlanmış ve filtre edilmiştir. Filtrat titre edildikten sonra kullanılan boya miktarına bağlı olarak askorbik asit miktarı mg $100 \mathrm{~g}^{-1}$ olarak hesaplanmıştır.

\section{Duyusal Analiz}

Meyveli dondurmaların duyusal özelliklerini belirlemek amacıyla tüketici testi kullanılmıştır. $\mathrm{Bu}$ amaçla 70 kişiye uygulanan tüketici testi ile dondurmaların sakızımsı yapı, tekstür, lezzet, yabancı tat, ağızda erime, erimeye dayanıklılık, meyve oranı ve genel kabul edilebilirlik gibi özellikleri bakımından beğeni durumları belirlenmiştir. Örneklerin değerlendirilmesinde 1: Hiç beğenmedim, 2: Beğenmedim, 3: Orta derecede beğenmedim, 4: Hafif beğenmedim, 5: Ne beğendim ne beğenmedim, 6: Orta derecede beğendim, 7: Az beğendim, 8: Pek çok beğendim, 9: Fevkalade beğendim olarak kabul edilmiştir (Meilgaard vd., 1999).

\section{İstatistiksel Analiz}

Araştırmadan elde edilen verilerin değerlendirilmesinde SPPS (SPSS 17 Corp. Inc.) istatistik paket programı kullanılmıştır. "Tek Yönlü Varyans Analizi (one-way ANOVA)" sonucunda önemli bulunan ana faktörlere Duncan Çoklu Karşılaştırma Testi uygulanmıştır. İstatistiksel farklılıkların ifade edilmesinde harfler kullanılmıştır.

\section{BULGULAR VE TARTIŞMA}

\section{Fizikokimyasal Özellikler}

Dondurma örneklerine ait fizikokimyasal analiz sonuçları Çizelge 1'de sunulmuştur. Dondurma örneklerinin \% kurumadde değerleri kivi ilavesinden istatistiksel olarak önemli düzeyde etkilenmiştir $(\mathrm{P}<0.01)$. Kurumadde değeri en yüksek " $(\% 36.10)$ " 
kontrol örneğinde (K), en düşük “(\%29.57)” ise KV16 örneğinde bulunmuştur (Çizelge 1). Kivi ilaveli dondurma örneklerinin kurumadde içeriklerinin kontrol örneğine göre daha düşük olduğu tespit edilmiştir. Goraya ve Bajwa (2015) yaptıkları çalışmada amla meyvesinin parçalarını ve püresini ilave ettikleri dondurmaların kurumadde değerlerinin kontrol örneğinden daha düşük olduğunu ve bu farkların istatistiksel olarak önemli olduğunu bulmuşlardır. Erkaya vd. (2012) tarafından yapılan çalışmada, altın çileği ilave ettikleri dondurma örneklerinin kurumadde değerlerinin daha yüksek olduğunu ve kurumadde değerlerinin \%29.31 ile $\% 35.20$ arasında değiştiğini tespit etmişlerdir. Bu çalışmada elde edilen sonuçlar Goraya ve Bajwa (2015)'nın sonuçları ile benzerlik gösterirken, Erkaya vd. (2012) tarafindan bulunan sonuçlardan farklılık arz etmiştir. İlave edilen kivinin örneklerin \% kül değerlerini önemli düzeyde etkilediği görülmüştür $(\mathrm{P}<0.01)$. Kontrol örneğinin kül değerinin diğer örneklerden daha yüksek olduğu tespit edilmiştir $(\mathrm{P}<0.05) . \% 12$ ve daha yüksek oranda yapılan kivi ilavesinin $\% 4$ ve \%8'lik ilaveye nazaran dondurma örneklerinin kül içeriklerini artırdığı belirlenmiştir. Kivi ilaveli dondurmalarda elde edilen kül değerlerinin Goraya ve Bajwa (2015) tarafindan bulunan değerlerden yüksek olduğu tespit edilmiştir.

Çizelge 1. Dondurma örneklerinin bazı fiziksel ve kimyasal özellikleri.

\begin{tabular}{|l|c|c|c|c|c|c|}
\hline \multicolumn{1}{|c|}{ Özellikler } & $\mathrm{K}$ & $\mathrm{KV} 4$ & $\mathrm{KV} 8$ & $\mathrm{KV} 12$ & $\mathrm{KV} 16$ & $\mathrm{KV} 20$ \\
\hline Kurumadde $(\%)$ & $36.10 \pm 0.01^{\mathrm{d}}$ & $31.57 \pm 0.88^{\mathrm{bc}}$ & $30.66 \pm 0.20^{\mathrm{b}}$ & $32.21 \pm 0.21^{\mathrm{c}}$ & $29.57 \pm 0.30^{\mathrm{a}}$ & $31.17 \pm 0.05^{\mathrm{b}}$ \\
\hline Kül (\%) & $1.04 \pm 0.07^{\mathrm{c}}$ & $0.82 \pm 0.01^{\mathrm{a}}$ & $0.82 \pm 0.05^{\mathrm{a}}$ & $0.91 \pm 0.00^{\mathrm{b}}$ & $0.88 \pm 0.01^{\mathrm{ab}}$ & $0.93 \pm 0.01^{\mathrm{b}}$ \\
\hline Asitlik (SH) & $14.02 \pm 0.08^{\mathrm{a}}$ & $14.16 \pm 0.44^{\mathrm{a}}$ & $18.05 \pm 1.16^{\mathrm{b}}$ & $20.91 \pm 0.44^{\mathrm{c}}$ & $22.72 \pm 0.02^{\mathrm{d}}$ & $24.71 \pm 0.28^{\mathrm{c}}$ \\
\hline $\mathrm{pH}$ & $6.44 \pm 0.02^{\mathrm{f}}$ & $6.19 \pm 0.04^{\mathrm{c}}$ & $6.00 \pm 0.01^{\mathrm{d}}$ & $5.83 \pm 0.01^{\mathrm{c}}$ & $5.66 \pm 0.00^{\mathrm{b}}$ & $5.45 \pm 0.02^{\mathrm{a}}$ \\
\hline Yağ(\%) & $4.90 \pm 1.17^{\mathrm{b}}$ & $4.25 \pm 0.07^{\mathrm{ab}}$ & $4.25 \pm 0.35^{\mathrm{b}}$ & $3.60 \pm 0.14^{\mathrm{ab}}$ & $3.25 \pm 0.07^{\mathrm{a}}$ & $3.25 \pm 0.07^{\mathrm{a}}$ \\
\hline İlk damlama (sn) & $1140.00 \pm 84.85^{\mathrm{a}}$ & $1585.00 \pm 219.20^{\mathrm{ab}}$ & $2115.00 \pm 106.07^{\mathrm{b}}$ & $1550.00 \pm 325.27^{\mathrm{ab}}$ & $1500.00 \pm 339.4 \mathrm{a}^{\mathrm{ab}}$ & $1620.00 \pm 339.41^{\mathrm{ab}}$ \\
\hline Tam erime (sn) & $3910.00 \pm 523.26^{\mathrm{a}}$ & $5100.00 \pm 339.41^{\mathrm{ab}}$ & $5550.00 \pm 0.26^{\mathrm{ab}}$ & $4440.00 \pm 848.53^{\mathrm{a}}$ & $5370.00 \pm 721.25^{\mathrm{ab}}$ & $6520.00 \pm 961.67^{\mathrm{b}}$ \\
\hline $\begin{array}{l}\mathrm{C} \text { vitamini (mg } \\
\begin{array}{l}100 \mathrm{~g}^{-1} \\
\text { kurumadde) }\end{array}\end{array}$ & $\mathrm{ND}^{\mathrm{a}}$ & $3.23 \pm 0.00^{\mathrm{b}}$ & $4.85 \pm 0.00^{\mathrm{c}}$ & $6.26 \pm 0.28^{\mathrm{d}}$ & $6.46 \pm 0.00^{\mathrm{d}}$ & $8.08 \pm 0.00^{\mathrm{e}}$ \\
\hline
\end{tabular}

a-f: Aynı satırdaki farklı harfler istatistiksel olarak farklılığı ifade etmektedir $(\mathrm{P}<0.05)$. K: kontrol grubu, KV4: \%4 (w/w) kivi eklenmiş, KV8: \%8 (w/w) kivi eklenmiş, KV12: \%12 (w/w) kivi eklenmiș KV16: \%16 (w/w) kivi eklenmiş, KV20: \%20 (w/w) kivi eklenmiş dondurma.

Dondurma örneklerinin $\mathrm{pH}$ ve asitlik ( $\left.{ }^{\circ} \mathrm{SH}\right)$ değerleri üzerine kivi ilavesinin etkisinin istatistiksel olarak önemli olduğu $(\mathrm{P}<0.01)$ tespit edilmiştir. Örneklerin $\mathrm{pH}$ değerlerinin kivi ilavesine bağlı olarak düştüğü ve bu farklılıkların istatistiksel olarak önemli olduğu $(\mathrm{P}<0.05)$ belirlenmiştir. $\mathrm{pH}$ değerlerinin 5.45 ile 6.44 arasında değiştiği ve en yüksek pH değeri kontrol örneğinde, en düşük değer ise KV20 örneğinde saptanmıştır. Erkaya vd. (2012) altın çileği ilave ederek ürettikleri dondurmaların $\mathrm{pH}$ değerlerinin 5.83-6.30 aralığında olduğunu belirlemişlerdir. Meyve ilaveli dondurmalardaki $\mathrm{pH}$ değişikliğinin meyvenin asitliği, polifenoller ile süt proteinleri arasındaki interaksiyonlar ve süte uygulanan pastörizasyon gibi işlemlerden kaynaklanabileceği bildirilmektedir (Sun-Waterhouse vd., 2013).

Örneklerin asitlik değerlerinin 14.02 ile 24.71 ${ }^{\circ} \mathrm{SH}$ arasında değiştiği, kontrol ile KV4 örneklerinin asitlik değerleri arasında istatistiksel olarak önemli bir farkın olmadığı $(\mathrm{P}>0.05)$, diğer örneklerin asitlik değerlerinin ise kivi miktarı ile doğru orantılı olarak arttığı belirlenmiştir (Çizelge 1). En yüksek asitlik değeri KV20 örneğinde tespit edilmiştir $(\mathrm{P}<0.05)$. Asitlik değerleri ile $\mathrm{pH}$ değerlerinin uyumlu olduğu, asitlik değerleri yükseldikçe $\mathrm{pH}$ değerlerinin de düştüğü ortaya konulmuştur. Erkaya vd. (2012) tarafından yapılan çalışmada altın çilek ilave edilen dondurmaların asitlik değerlerinin 9.72-14.66 ${ }^{\circ} \mathrm{SH}$ arasında olduğu ve meyve ilavesiyle ${ }^{\circ} \mathrm{SH}$ değerlerinin yükseldiği saptanmıştır. Dondurma örneklerinin yă̆ oranları üzerine kivi ilavesinin etkisinin istatistiksel olarak önemsiz $(\mathrm{P}>0.05)$ olduğu tespit edilmiştir. En yüksek yağ oranı $\% 4.90$ olarak kontrol örneğinde, en düşük yağ oranı \%3.25 olarak KV16 ve KV20 örneklerinde $(\mathrm{P}<0.05)$ belirlenmiştir (Çizelge 1). Dondurma örneklerinde kivi ilavesiyle yağ oranlarının düştüğü $(\mathrm{P}<0.05), \mathrm{KV} 4, \mathrm{KV} 8$ ve KV12 örneklerinin yağ oranları arasında istatistiksel olarak önemli bir farkın olmadığı $(\mathrm{P}>0.05)$ belirlenmiştir. Akalın vd. (2008) ve Karaman vd. (2014) tarafindan yapılan çalışmada dondurma örneklerinin yăg oranlarının ilave edilen katkılarla birlikte düştüğü tespit edilmiştir.

İlk damlama ve tam erime zamanlarına ait değerlerin kivi ilavesinden etkilenmediği $(\mathrm{P}>0.05)$ belirlenmiştir. Dondurma örneklerinin ilk damlama değerleri 1140 sn ile 2115 sn arasında değiştiği tespit edilmiştir. En düşük ilk damlama değeri 1140 sn ile kontrol örneğinde, en yüksek değer ise 2115 sn ile KV8 örneğinde belirlenmiştir $(\mathrm{P}<0.05)$. KV12, KV16 ve KV20 örneklerinin ilk damlama değerleri arasında istatistiksel olarak önemli bir farkın olmadığı $(\mathrm{P}>0.05)$ ortaya konulmuştur. Yapılan bir araştırmada, limon lifi ilave edilen dondurmaların ilk damlama sürelerinin 2316 sn ile 2850 sn arasinda 
değiştiği belirlenmiştir (Dervisoglu ve Yazici 2006). Başka bir çalışmada ise farklı emülgatörlerin farklı oranlarda ilave edildiği dondurma örneklerinin ilk damlama sürelerinin 2926-7213 sn arasında olduğu tespit edilmiştir (Atsan ve Çağlar, 2008). Aslaner ve Salık (2017) dondurma örneklerinin ortalama ilk damlama zamanını 344 s olarak bulmuşlardır. Bu çalışmada bulunan değerler Atsan ve Çağlar (2008)'in bulduğu değerlerden daha düşük, Aslaner ve Salık (2017)'ın elde ettiği değerlerden yüksek olduğu ortaya konulmuştur.

Tam erime zamanına ait değerlerin kivi ilavesiyle düzensiz bir değişim gösterdiği, bu değişimlerin istatistiksel olarak önemli olduğu belirlenmiştir $(\mathrm{P}<0.05)$. En yüksek tam erime zamanı 6520 sn ile KV20 örneğinde, en düşük ise 3910 sn ile kontrol örneğinde tespit edilmiştir. $(\mathrm{P}<0.05)$. KV4, KV8 ve KV12 örneklerinin tam erime zamanlarının kontrol örneğine göre daha yüksek olduğu $(\mathrm{P}<0.05)$ ortaya konulmuştur. Dondurma üretiminde farklı hidrokolloidlerin kullanıldığı örneklerde tam erime zamanlarının 3208 sn ile 7796 sn arasında olduğu bulunmuştur (Şimşek vd., 2006). Aslaner ve Salık (2017) yaptıkları çalışmada dondurma örneklerinin ortalama tam erime zamanını 5297 sn olarak belirlemişlerdir. Diyet lifler yüksek su bağlama kapasitesine sahip olduklarından dondurmaların tekstürel özelliklerine olumlu yönde katk1 sağlarlar (Dervisoglu ve Yazici, 2006). İlk damlama ve tam erime zamanlarının meyve ilavesine bağlı olarak yükselmesinde meyvelerin içerdikleri diyet lifinin rolü olduğu düşünülmektedir.

Dondurma örneklerinin 20,30,50, 60 ve 100 rpm'deki viskozite değerlerinin kivi ilavesinden etkilenmediği $(\mathrm{P}>0.05)$ belirlenmiştir. KV4, KV8 ve KV12 örneklerinin ise $20 \mathrm{rpm}$ 'de ölçülen viskozite değerlerinin diğer örneklerden daha yüksek olduğu $(\mathrm{P}<0.05)$ tespit edilmiştir (Şekil 1). Kontrol örneğinin $30,50,60$ ve 100 rpm'deki viskozite değerlerinin diğer örneklerden düşük olduğu fakat bu farkın istatistiksel olarak önemli olmadığ $\quad(\mathrm{P}>0.05)$ belirlenmiştir. Kivi ilavesine bağlı olarak dondurma örneklerinin 30, 50, 60 ve 100 rpm'deki viskozite değerlerinin değiştiği, bu değişimlerin ise önemli olmadığı $(\mathrm{P}>0.05)$ ortaya konulmuştur. Meyvelerdeki diyet lif içeriğinin viskozite üzerinde etkili olduğu bildirilmiştir (Ramadan and Moersel, 2009).

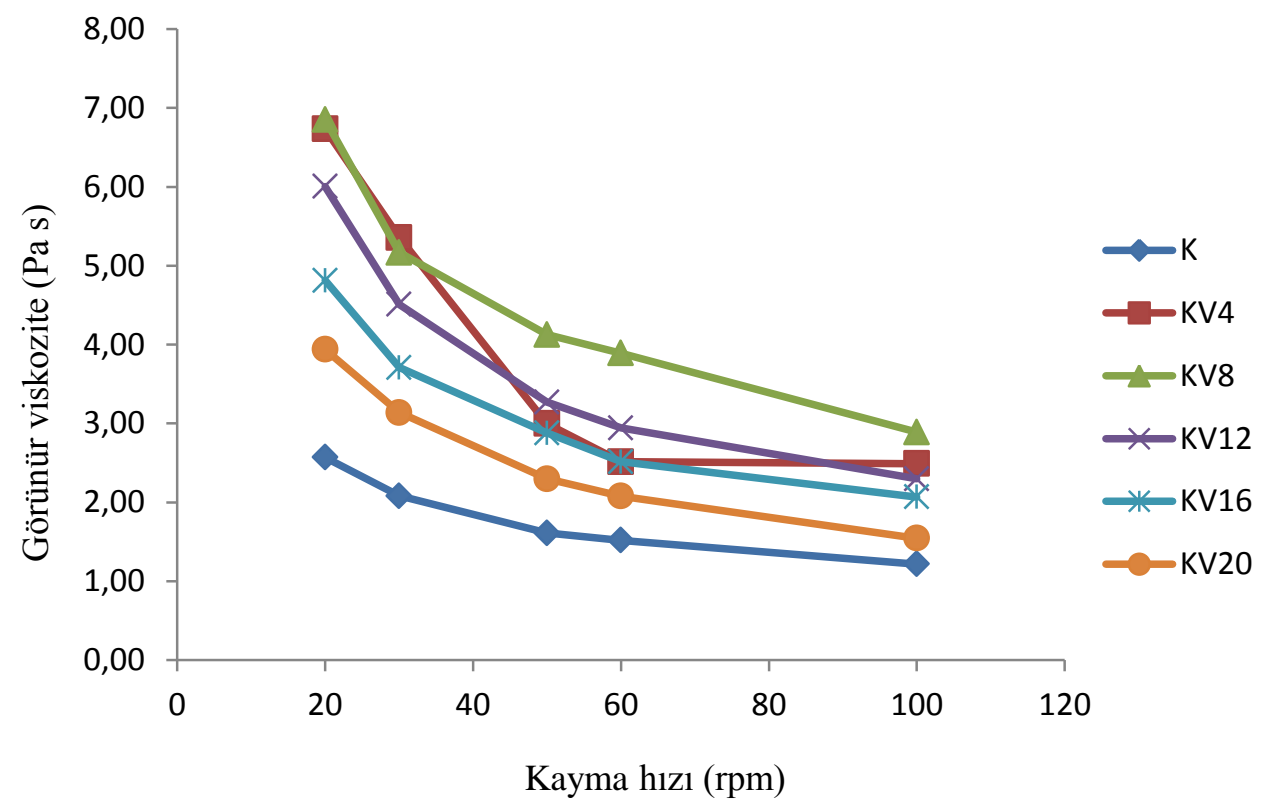

Şekil 1. Dondurma örneklerinde kayma hızı ile görünür viskozite arasındaki ilişki.

K: kontrol grubu, KV4: \%4 (w/w) kivi eklenmiş, KV8: \%8 (w/w) kivi eklenmiş, KV12: \%12 (w/w) kivi eklenmiş KV16: \%16 $(\mathrm{w} / \mathrm{w})$ kivi eklenmiş, KV20: \%20 (w/w) kivi eklenmiş dondurma

Akışkanlar, akış davranış indeksi (n) 1 ise Newtonian davranış, $0<\mathrm{n}<1$ ise psödoplastik, $\mathrm{n}>1$ ise dilitant akış olarak ifade edilir (Steffe, 1967). Bu çalışmada, tüm dondurma örneklerinin psödoplastik akış gösterdiği belirlenmiştir (Çizelge 2). Benzer şekilde, dondurma üzerine yapılan başka bir çalışmada dondurma örneklerinin psödoplastik akış davranışı gösterdiği tespit edilmiştir (Akalın vd., 2008). Dondurmaların kıvam indeksinin yüksek olması örneklerin viskozitelerinin yüksek olduğunu göstermektedir (Akalın vd., 2008). En yüksek kıvam indeksi KV4 örneğinde bulunmuştur. 
Çizelge 2. Dondurma örneklerinin reolojik özellikleri.

\begin{tabular}{|c|c|c|c|}
\hline Dondurma örnekleri & $\mathrm{K}$ (kıvamlılık katsayıs1) & $\mathrm{n}$ (akış davranış indeksi) & $\mathrm{r}^{2}$ \\
\hline $\mathrm{K}$ & 10.166 & 0.536 & 0.996 \\
\hline $\mathrm{KV} 4$ & 52.401 & 0.302 & 0.896 \\
\hline KV8 & 31.312 & 0.484 & 0.991 \\
\hline KV16 & 35.271 & 0.399 & 0.993 \\
\hline KV20 & 22.817 & 0.471 & 0.991 \\
\hline
\end{tabular}

K: Kontrol grubu, KV4: \%4 (w/w) kivi eklenmiş, KV8: \%8 (w/w) kivi eklenmiş, KV12: \%12 (w/w) kivi eklenmiş KV16: \%16 (w/w) kivi eklenmiş, KV20: \%20 (w/w) kivi eklenmiş dondurma.

\section{Vitamini}

C vitamini insanların gidalarla alması gereken, biyolojik olarak aktif olan maddelerin en önemlilerinden bir tanesidir. $\mathrm{C}$ vitamini demir emilimi için de gereklidir. $\mathrm{Bu}$ nedenle $\mathrm{C}$ vitamini gıdaların kalitesini iyileştirmek için katkı maddesi olarak sıkça kullanılmaktadır (Bai vd., 2014). C vitamini oksidasyonu önlediği için antioksidan özelliğine sahip bir vitamindir (Padayatty vd., 2003; Bai vd., 2014). Sütte C vitamini miktarı çok düşüktür (Bai vd., 2014). C vitamini, stabilitesi çok düşük vitaminler arasındadır ve oksidasyona karşı çok hassastır. Metal iyonları, sıcaklık ve 1 şı C vitamininin oksidasyonunu hızlandırmaktadır. $\mathrm{Bu}$ nedenle süt ürünlerinin üretiminde kullanılan teknolojik işlemler son üründeki $\mathrm{C}$ vitamini miktarını etkilemektedir (Bai vd., 2014; Martysiak-Zurowska vd., 2017).

Dondurma örneklerinde kullanılan kivinin C vitamini miktarı $43.64 \mathrm{mg} 100 \mathrm{~g}^{-1}$ olarak bulunmuştur. Park vd. (2011) yaptığ1 çalışmada kivilerin $\mathrm{C}$ vitamini içeriğinin $6.56 \mathrm{mg} \mathrm{g}^{-1}$ ile $152 \mathrm{mg}$ $\mathrm{g}^{-1}$ arasında değiştiğini ortaya koymuşlardır. Ekşi ve Türkmen Özen (2012) yaptıkları çalışmada kivinin C vitamini içeriğini $100 \mathrm{mg} \mathrm{g}^{-1}$ olarak bulmuşlardır. $\mathrm{Bu}$ araştırmada, dondurmanın $\mathrm{C}$ vitamini değerlerinin kivi ilavesinden istatistiksel olarak önemli düzeyde $(\mathrm{P}<0.01)$ etkilendiği tespit edilmiştir. En yüksek $\mathrm{C}$ vitamini değeri (8.08 mg $100 \mathrm{~g}^{-1}$ ) \%20 kivi oranına sahip KV20 örneğinde bulunmuştur (Çizelge 1). En düşük $\mathrm{C}$ vitamini değeri ise kontrol örneğinde tespit edilmiștir $(\mathrm{P}<0.05)$. Dondurma örneklerindeki kivi konsantrasyonunun artmasına bağlı olarak $\mathrm{C}$ vitamini değerlerinin yükseldiği belirlenmiștir $\quad(\mathrm{P}<0.05)$. Topdaş vd. (2017) kızılcık ilaveli dondurma örneklerinin C vitamini içeriklerinin $<0.6 \mathrm{mg} 100 \mathrm{~g}^{-1}$ ile $18.3 \mathrm{mg} 100 \mathrm{~g}^{-1}$ arasında olduğunu, Çakmakçi vd. (2016) kumkuat ilaveli dondurmalarda ise $<0.6 \mathrm{mg}$ $100 \mathrm{~g}^{-1}$ ile $13.40 \mathrm{mg} 100 \mathrm{~g}^{-1}$ arasında değiştiğini bulmuşlardır. $\mathrm{Bu}$ araştırmada kivi ilaveli dondurmaların $\mathrm{C}$ vitamini içeriklerinin yüksek olmasının nedeni kivinin önemli $\mathrm{C}$ vitamini kaynaklarında bir tanesi olmasıdır.

\section{Duyusal Özellikler}

Dondurma örneklerinin renk, sakızımsı yapı $(\mathrm{P}<0.01)$, tekstür, lezzet, yabancı tat ve ağızda erime $(\mathrm{P}<0.05)$ özelliklerinin kivi ilavesinden etkilendiği, erimeye dayanıklılık, meyve oranı ve genel kabul edilebilirlik değerlerinin ise etkilenmediği $(\mathrm{P}>0.05)$ ortaya konulmuştur. KV4 örneğinin renk değerlerinin diğer kivi ilaveli dondurmalardan daha yüksek olduğu $(\mathrm{P}<0.05), \mathrm{KV} 8, \mathrm{KV} 12, \mathrm{KV} 16$ ve KV20 örnekleri arasında önemli bir farklılığın olmadığ1 belirlenmiştir. KV4 örneğinin sakızımsı yapı (6.94), tekstür (6.93), lezzet (6.40) ve erimeye dayanıklılık (6.49) bakımından en yüksek puanlara sahip olduğu tespit edilmiştir. Kontrol örneğinin ağızda erime (6.62) puanının diğer örneklerden daha yüksek olduğu saptanmıştır. Meyve oranı bakımından \%4 ve \%8 kivi ilaveli dondurma örnekleri en yüksek puanları almıştır. Dondurma örnekleri arasında KV4 örneğinin en çok beğenilen (6.44) örnek olduğu belirlenmiştir. KV12, KV16 ve KV20 örnekleri diğer örneklere göre daha az beğenilmiştir $(\mathrm{P}<0.05)$.

Çizelge 3. Dondurma örneklerinin duyusal özellikleri.

\begin{tabular}{|l|c|c|c|c|c|c|}
\hline Duyusal & K & KV4 & KV8 & KV12 & KV16 & KV20 \\
\hline Renk & $7.29 \pm 0.02^{\mathrm{b}}$ & $7.32 \pm 0.03^{\mathrm{b}}$ & $6.45 \pm 0.35^{\mathrm{a}}$ & $6.50 \pm 0.08^{\mathrm{a}}$ & $6.65 \pm 0.16^{\mathrm{a}}$ & $6.55 \pm 0.23^{\mathrm{a}}$ \\
\hline Sakızıms1 yap1 & $6.06 \pm 0.08^{\mathrm{a}}$ & $6.94 \pm 0.04^{\mathrm{c}}$ & $6.30 \pm 0.01^{\mathrm{b}}$ & $5.97 \pm 0.46^{\mathrm{ab}}$ & $5.65 \pm 0.30^{\mathrm{a}}$ & $5.54 \pm 0.07^{\mathrm{a}}$ \\
\hline Tekstür & $6.43 \pm 0.10^{\mathrm{ab}}$ & $6.93 \pm 0.18^{\mathrm{b}}$ & $6.16 \pm 0.08^{\mathrm{a}}$ & $6.15 \pm 0.45^{\mathrm{a}}$ & $5.80 \pm 0.20^{\mathrm{a}}$ & $5.79 \pm 0.40^{\mathrm{a}}$ \\
\hline Lezzet & $6.18 \pm 0.37^{\mathrm{bc}}$ & $6.40 \pm 0.38^{\mathrm{c}}$ & $5.89 \pm 0.36^{\mathrm{abc}}$ & $5.59 \pm 0.13^{\mathrm{ab}}$ & $5.19 \pm 0.30^{\mathrm{a}}$ & $5.27 \pm 0.18^{\mathrm{a}}$ \\
\hline Yabanc1 tat & $6.06 \pm 0.45^{\mathrm{c}}$ & $6.15 \pm 0.08^{\mathrm{c}}$ & $5.63 \pm 0.18^{\mathrm{abc}}$ & $5.80 \pm 0.04^{\mathrm{bc}}$ & $5.21 \pm 0.15^{\mathrm{a}}$ & $5.49 \pm 0.08^{\mathrm{ab}}$ \\
\hline Ağıda erime & $6.62 \pm 0.59^{\mathrm{c}}$ & $6.30 \pm 0.18^{\mathrm{bc}}$ & $5.52 \pm 0.03^{\mathrm{a}}$ & $5.90 \pm 0.06^{\text {abc }}$ & $5.45 \pm 0.26^{\mathrm{a}}$ & $5.67 \pm 0.18^{\mathrm{ab}}$ \\
\hline Erimeye dayan1klılik & $5.69 \pm 0.40^{\mathrm{a}}$ & $6.49 \pm 0.08^{\mathrm{b}}$ & $5.96 \pm 0.14^{\mathrm{ab}}$ & $6.53 \pm 0.33^{\mathrm{b}}$ & $6.03 \pm 0.19^{\mathrm{ab}}$ & $5.87 \pm 0.32^{\mathrm{ab}}$ \\
\hline Meyve oranı & $3.97 \pm 0.48^{\mathrm{a}}$ & $5.07 \pm 0.47^{\mathrm{ab}}$ & $5.37 \pm 0.48^{\mathrm{b}}$ & $5.55 \pm 0.49^{\mathrm{b}}$ & $5.78 \pm 0.54^{\mathrm{b}}$ & $5.90 \pm 0.70^{\mathrm{b}}$ \\
\hline Genel kabul edilebilirlik & $6.14 \pm 0.04^{\mathrm{ab}}$ & $6.44 \pm 0.15^{\mathrm{b}}$ & $5.90 \pm 0.23^{\mathrm{ab}}$ & $5.69 \pm 0.21^{\mathrm{a}}$ & $5.59 \pm 0.03^{\mathrm{a}}$ & $5.59 \pm 0.45^{\mathrm{a}}$ \\
\hline
\end{tabular}

a-f: Aynı satırdaki farklı harfler istatistiksel olarak farklılı̆g ifade etmektedir $(\mathrm{P}<0.05)$. K: kontrol grubu, KV4: \%4 (w/w) kivi eklenmis, KV8: \%8 (w/w) kivi eklenmiş, KV12: \%12 (w/w) kivi eklenmiş KV16: \%16 (w/w) kivi eklenmiş, KV20: \%20 (w/w) kivi eklenmiş dondurma 
Atatürk Üniv. Ziraat Fak. Derg., 49 (2): 111-117, 2018

Atatürk Univ., J. of the Agricultural Faculty, 49 (2): 111-117, 2018 ISSN : 1300-9036

\section{SONUC}

Dondurma tüm dünyada her yaştaki tüketici tarafindan sevilerek tüketilen bir dondurulmuş süt tatlısıdır. Her gün yeni formülasyonlara sahip dondurmalar ise market raflarında yerini almaktadır. $\mathrm{Bu}$ araştırmada kivi ilavesinin dondurma örneklerinin bazı fizikokimyasal (kurumadde, kül, asitlik, $\mathrm{pH}$ ve $\mathrm{C}$ vitamini) özelliklerini etkilediği $\quad(\mathrm{P}<0.01)$ belirlenmiştir. Aynı zamanda, kivi ilavesinin dondurmaların kıvamını yükselttiği ortaya konulmuştur. Duyusal özelliklerden ise renk, sakızıms1 yap1 $(\mathrm{P}<0.01)$, tekstür, lezzet, yabanc1 tat ve ağızda erime $(\mathrm{P}<0.05)$ puanları üzerine kivi ilavesinin etkisinin önemli olduğu tespit edilmiştir. KV4 örneği ise dondurma örnekleri arasında en çok beğenilen dondurma örneği olmuştur. Sonuç olarak, kivi ilavesinin dondurmaların $C$ vitamini içeriğini ve kıvamını arttırmak için kullanılabileceği ortaya konulmuş olup duyusal açıdan ise en ideal oranın \%4 olduğu belirlenmiştir.

\section{KAYNAKLAR}

Akalın, A.S. Karagözlü, C. Ünal, G., 2008. Rheological properties of reduced-fat and lowfat ice cream containing whey protein isolate and inulin. Eur. Food Res. Technol., 227:889895.

Akin, M.B. Akin, M.S. Kirmaci, Z., 2007. Effects of inulin and sugar levels on the viability of yogurt and probiotic bacteria and the physical and sensory characteristics in probiotic ice-cream. Food Chem., 104:93-99.

Aslaner, A. Salık, M.A., 2017. Ceviz ezmesi ve dut kurusu tozu ilavesiyle üretilen düşük kalorili dondurmanın bazı kalite niteliklerinin belirlenmesi. Atatürk Üniv. Ziraat Fak. Derg., 48 (1):57-64.

Atsan, E. Çăglar, A., 2008. Dondurmanın bazı fiziksel ve duyusal özellikleri üzerine farklı emülgatörlerin etkisi. Atatürk Üniv. Ziraat Fak. Derg., 39 (2):75-81.

Bai, Y. Saren, G. Huo, W., 2014. Response surface methodology (RSM) in evaluation of the vitamin $\mathrm{C}$ concentrations in microwave treated milk. J. Food Sci. Technol., 52 (7):4647-4651.

Çakmakçi, S. Topdaş, E.F. Çakir, Y. Kalin, P. 2016. Functionality of kumquat (Fortunella margarita) in the production of fruity ice cream. J. Sci. Food Agric., 96:1451-1458.

Demirci, M. Gündüz, H.H., 1994. Süt Teknoloğunun El Kitabı. Hasad Yayınları, İstanbul.

Dervisoglu, M. Yazici, F., 2006. Note. The effect of citrus fibre on the physical, chemical and sensory properties of ice cream. Food Sci, Technol, Int., 12 (2):159-164.

Du, G. Li, M. Ma, F. Liang, D., 2009. Antioxidant capacity and the relationship with polyphenol
Araştırma Makalesi/Research Article

and Vitamin C in Actinidia fruits. Food Chem., 113:557-562.

Ekşi, A. Türkmen Özen, İ., 2012. Kivi meyvesinin kimyasal bileşenleri ve fonksiyonel özellikleri. Ordu Üniversitesi Bilim ve Teknol. Derg., 2 (2):54-67.

Erkaya, T. Dağdemir, E. Sengül, M., 2012. Influence of Cape gooseberry (Physalis peruviana L.) addition on the chemical and sensory characteristics and mineral concentrations of ice cream. Food Res. Int., 45:331-335.

Goraya, R.K. Bajwa, U., 2015. Enhancing the functional properties and nutritional quality of ice cream with processed amla (Indian gooseberry). J. Food. Sci. Technol., 52 (12):7861-7871.

Güven, M. Karaca, O.B., 2002. TThe effects of varying sugar content and fruit concentration on the physical properties of vanilla and fruit icecream-type frozen yogurts. Int. J. Dairy Technol., 55 (1):27-31.

Karaman, S. Toker, Ö.S. Yüksel, F. Çam, M. Kayacier, A. Dogan, M., 2014. Physicochemical, bioactive, and sensory properties of persimmon-based ice cream: Technique for order preference by similarity to ideal solution to determine optimum concentration. J. Dairy Sci., 97:97-110.

Kavaz Yuksel, A., 2015. The effects of blackthorn (Prunus spinosa L.) addition on certain quality characteristics of ice cream. J. Food Qual., 38:413-421.

Kılıç, O. Sıray, E., 2016. Türkiye'de kivi üretici birliklerinin mevcut durumu, sorunları ve çözüm önerileri. Türkiye Tarımsal Araştırmalar Derg., 3:74-78.

Martysiak-Zurowska, D. Puta, M. Barczak, N. Dabrowska, J. Malinowska-Pańczyk, E. Kiełbratowska, B. Kołodziejska, I., 2017. Effect of high pressure and sub-zero temperature on total antioxidant capacity and the content of vitamin C, Fatty acids and secondary products of lipid oxidation in human milk. Polish J. Food Nutr. Sci., 67 (2):117-122.

Meilgaard, M.C. Carr, B.T. Civille, G.V., 1999. Sensory Evaluation Techniques. CERC Press, New York.

Özkan, M. Kırca, A. Cemeroğlu, B., 2007. Gıdalarda Uygulanan Bazı Özel Analiz Yöntemleri. In: Cemeroğlu, B., (ed) Gıda Analizleri. 87-156. Gıda Teknolojisi Derneği Yayınları No:34.

Padayatty, S.J. Katz, A. Wang, Y. Eck, P. Kwon, O. Lee, J.H. Chen, S. Corpe, C. Levine, M. Dutta, A. Dutta, S.K., 2003. Vitamin C as an antioxidant: evaluation of 1 ts role in disease prevention. J. Am. Coll. Nutr., 22 (1):18-35.

Park, Y.S. Leontowicz, H., Leontowicz, M. 
Namiesnik, J. Suhaj, M. Cvikrová, M. Martincová, O. Weisz, M. Gorinstein, S., 2011. Comparison of the contents of bioactive compounds and the level of antioxidant activity in different kiwifruit cultivars. J. Food Compos. Anal., 24:963-970.

Ramadan, M.F. Moersel, J.T., 2009. Oil extractability from enzymatically treated goldenberry (Physalis peruviana L.) pomace: Range of operational variables. Int. J. Food Sci. Technol., 44:435-444.

Sikora, E. Bieniek, M.I. Barbara, B., 2013. Composition and antioxidant properties of fresh and frozen stored blackthorn fruits (Prunus spinosa L.). Acta Sci. Pol. Technol. Aliment., 12 (4):365-372.

Soukoulis, C. Fisk, I.D. Bohn, T., 2014. Ice cream as a vehicle for incorporating health-promoting ingredients: Conceptualization and overview of quality and storage stability. Compr. Rev. Food Sci. Food Saf., 13:627-655.

Soukoulis, C. Lebesi, D. Tzia, C., 2009. Enrichment of ice cream with dietary fibre: Effects on rheological properties, ice crystallisation and glass transition phenomena. Food Chem., 115:665-671.

Steffe, J.F., 1967. Rheological Methods in Food Process Engineering. Freeman Press, East Lansing, MI.

Sun-Waterhouse, D. Edmonds, L. Wadhwa, S.S. Wibisono, R., 2013. Producing ice cream using a substantial amount of juice from kiwifruit with green, gold or red flesh. Food Res. Int., 50:647-656.

Şimşek, O. Tuncay, İ. Bilgin, B., 2006. Endüstriyel dondurma üretiminde farklı stabilizatör kullanımının dondurma kalitesine etkisi. Tekirdağ Ziraat Fak. Derg., 3 (1):55-63.

Topdaş, E.F. Çakmakçı, S. Çakıroğlu, K., 2017. TThe antioxidant activity, vitamin $\mathrm{C}$ contents, physical, chemical and sensory properties of ice cream supplemented with cornelian cherry (Cornus mas L.) paste. Kafkas Univ. Vet. Fak. Derg., 23 (5): 691-697. 